\title{
Consideraciones sobre el fin de la bipolaridad*
}

Ramón Cotarelo

UMIPOLARIDAD FORMAL, MULTIPOLARIDAD REAL

INTRODUCCION

Enn nuestra época nos ha correspondido vivir un acontecimiento que, por su carácter hubiera sido impensable solo hace 10 años: el hundimiento del comunismo. Las jornadas siguientes al 19 de agosto de 1991, en las que se puso fuera de la legalidad al PCUS en la URSS marcan el final de un siglo que, a los efectos nuestros, había comenzado en 1917. Todavía hoy, en 1992, y seguramente en muchos años con posterioridad, no acabamos de entender en toda su magnitud un episodio de esta naturaleza que, por sus consecuencias, los historiadores del futuro quizá comparen con otros hitos de la historia mundial, es posible que con la caída del lmperio Romano y, desde luego, con las revoluciones de 1789 y 1917.

En verdad, las razones del hundimiento del comunismo son complejas y requieren un estudio pormenorizado (1) y estamos seguramente lejos de llegar a un acuerdo. No cabe duda de que, entre aquéllas, destacan con gran evidencia las de carácter económico y social. En otros términos, la URSS se ha hundido como 
potencia múndial bajo el peso de una catástrofe económica sin precedentes y de la que es único responsable el PCUS, un partido fundado en la doctrina "científica" de Karl Marx, pero incapaz de organizar un sistema económico productivo medianamente viable (2). Y no solamente éstas. También han sido decisivas las tensiones étnicas y nacionalistas en el antiguo imperio zarista, transformado por Lenin en el supuesto ámbito libre del internacionalismo proletario (3). En pocos aspectos se verá con mayor claridad la enorme distancia entre realidad y ficción que siempre caracterizó al comunismo soviético (4) como en éste de las nacionalidades. Amparado en la doctrina leninista al respecto, debidamente continuada por Stalin (5), el comunismo sostuvo haber resuelto un problema hasta entonces sin solución como el de la convivencia pacífica de distintas naciones bajo una sola estructura política en el ámbito de la URSS. Y hacerlo, además, en términos teóricos satisfactorios, desde el momento en que remitía el sentimiento nacional a una emanación de la condición clasista, felizmente superada por la revolución. Por último, entre aquellas razones no cabe ignorar, claro es, los sacrificios y la permanente voluntad de las poblaciones del interior del llamado "telón de acero" de sacudirse el asfixiante yugo de la dictadura del partido único, que no paraba de hablar en términos absurdos acerca de la naturaleza del propio régimen político, como si fuera el orden de lo salvífico (6).

Probablemente todas las interpretaciones contengan una porción de verdad y ninguna la haga justicia por entero. De sobra sabemos ya que las explicaciones monocausales no son satisfactorias. En el caso del hundimiento del comunismo, además, la acumulación de informaciones empíricas de que se dispone ya no deja lugar a dudas respecto a que su explicación es claramente multicausal: Los indicadores de la actividad económica son terminantes. EI PIB de los países comunistas era sólo una fracción del de los países capitalistas que les fueran comparables (7). En el momento del comienzo de la transición del socialismo al capitalismo - que es lo que, por ironía de la historia, se han visto obligados a hacer estos países-, las tasas de inflación y los índices de descenso de la producción industrial (8) prueban que hemos de habérnoslas con Estados en situación económica catastrófica que, en otras circunstancias, hubiéramos asimilado a países del llamado Tercer Mundo. Por supuesto, cualesquiera otros indicadores revelan situaciones similares; por ejemplo, los de contaminación y destrucción de los recursos naturales no renovables o simple esquilmación de la tierra (9) por regiones explican en buena medida este resurgir violento y exacerbado de los nacionalismos, que se rebelan contra la imposición centralista no ya en términos lingüísticos o culturales, sino directamente en los aspectos de gestión de los recursos propios y administración del propio patri- 
monio (10). Finalmente, los indicadores de carácter social, como la esperanza media de vida (de las más bajas de Europa, o la tasa de mortalidad infantil (de.las más altas), sin contar con otros no menos reveladores, como los niveles de consumo (11) explican, a su vez, la cerrada y cuasi universal oposición de los pueblos de estos países a sus regímenes políticos. Tales indicadores dan también àl traste con las más caracterizadas patrañas de consumo frecuente en Occidente a la hora de justificar los sistemas comunistas, esto es, la de que, si bien eran regímenes carentes de libertades, cuando menos, las poblaciones gozaban de asistencia y prestaciones sociales universales y de calidad (sistema educativo, sanitario, etc.).

Se puede debatir acerca del verdadero alcance del hundimiento comunista en términos teóricos (12) y seguramente seguirá haciéndose en los años próximos. No hay duda, sin embargo, de que tal hundimiento ha contribuido decisivamente a transformar el orden internacional. Como se daba por supuesto algo más arriba, el sistema comunista ha quebrado bajo el peso de sus insuficiencias y contradicciones internas, sin necesidad de una confrontación bélica (como fue el caso con los fascismos). Pero ello no quiere decir que no se haya producido una confrontación también en el terreno estrictamente militar, aunque sea por nación interpuesta, donde el comunismo tampoco ha mostrado capacidad para resistir el envite de los Estados capitalistas. Es perfectamente sostenible hoy que la Guerra del Golfo terminó con el mito de la bipolaridad mundial ya que en ella los Estados Unidos combatieron prácticamente en solitario, con una escasa aunque valiosa ayuda de ingleses, franceses y algunos países árabes y contra un ejército en lo esencial pertrechado por la URSS. De hecho, ya en las otras guerras de Oriente próximo, el material bélico de fabricación soviética había mostrado su notable inferioridad frente al occidental, en concreto, el estadounidense.

Todos los comentaristas y observadores coinciden en señalar que entramos en una era de pax americana (13). En efecto, cualquiera que esté medianamente atento al sucederse de los acontecimientos internacionales no podrá por menos de levantar constancia de cómo éstos aparecen determinados por las opciones estadounidenses exclusivamente. Las imágenes del correspondiente secretario yanqui de Estado viajando por los cinco continentes y mediando en todos los conflictos, al superponerse sobre las del desastroso derrumbarse de la ficción comunista, deja escaso margen a otras opiniones. En principio, los EEUU parecen dominar el mundo casi como, mutatis mutandis, en tiempos del.Imperio lo hiciera Roma con el entonces conocido. De aplicar aquí un criterio tradicional, habría que admitir -bien fuera por vía de Realpolitik, bien por otra de resolución ideológica (14) que asiste a 
los EEUU un derecho (y quizá un deber) incontrovertible de pacificar el orden internacional a base de intervenir en todos los contenciosos para prevenir o zanjar los conflictos. Ahora bien, esta interpretación plantea algunos problemas delicados de viabilidad y de conexión con las condiciones reales del mundo que no cabe desconocer y que determinan decisivamente la forma en que se articula dicha pax americana. Tales problemas son de tres tipos: económicos, morales y políticos.

\section{PROBLEMAS ECONOMTCOS}

Desde el punto de vista económico y de la potencia productiva e industrial, los EEUU pueden policiar el mundo, evidentemente, pero no está claro que puedan pagar por ello; es decir, no está claro que tengan la capacidad financiera pará sostener su empeño arbitral. La distribución de los costos de la Guerra del Golfo ha puesto bien en claro esta dificultad. Los norteamericanos han insistido en que sus aliados pechen con una parte considerable de las deudas, en especial en los casos del Japón y de Alemania (15). Si añadimos a este requerimiento las cuantiosas aportaciones de Arabia Saudí y Kuwait veremos cómo, en efecto, el ejército norteamericano, el primero del mundo, se encuentra en la situación de la tropa mercenaria; un dato que algunos podrán utilizar para mantener la imagen de la decadencia de la gran potencia imperial (16), siempre en la onda de la comparación con el Imperio romano.

De hecho, la hegemonía estadounidense indiscutible en el terreno militar ha de coexistir con una hegemonía financiera que ya no corresponde a los EEUU, sino a Japón en primer lugar y a la Comunidad Europea en segundo ( $y$, dentro de la CE, a Alemania). De los 50 bancos más importantes del mundo, los 4 primeros son Japoneses (17). Se da; por lo tanto, una paradójica situación en este caso en que la potencia militarmente dominante no es - ni puede ser- la económicamente dominante y se atisba, en consecuencia, la tesis que se pretende mantener en este trabajo, esto es, que la unipolaridad actual sólo es posible en la medida en que la potencia hegemónica respete las reglas establecidas por otros Estados o entidades en una situación que, en términos reales, es una multipolaridad. Evidentemente, nádie imagina hoy que los EEUU puedan poner fin a su situación de relativa supeditación financiera y económica en general á base de mandar las tropas al Japón o a Alemania.

La debilidad económica de los Estados Unidos (debilidad, claro es, por relación a los otros dos gigantes) se refleja en su enorme déficit presupuestario, 
financiado a través de la absorción masiva de capital extranjero, en especial japonés que está adueñándose literalmente del país. Que esta situación a su vez dé lugar a un peligro cierto de orientación autoritaria e, incluso, antidemocrática en los EEUU es una hipótesis improbable, aunque no imposible, si bien queda lejos de los intereses de este trabajo (18). El hecho aquí indubitable es que, en la actual contradicción entre manteniniento de las prerrogativas de soberanía de los Estados y transnacionalización del capital, Norteamérica no escapa a la situación general y no puede permitirse el lujo de un retorno a la vieja actitud aislacionista porque su imbricación (e imbricación supeditada en buena medida) se lo impide.

A su vez, esta circunstancia, aparentemente paradójica en el terreno financiero, tiene su correlato en los demás, en especial en el productivo y comercial. El déficit presupuestario de los EEUU, el mayor del mundo, equivalente a la deuda exterior de todos los países subdesarrollados (19) se origina en parte en su balanza comercial deficitaria y, dentro de ese déficit comercial, en el comercio con el Japón (20). Las amargas quejas acerca de las prácticas comerciales ilícitas de los japoneses, no pasan de ser jeremiadas con las que los norteamericanos mezclan a veces veladas amenazas, pero que únicamente pretenden ocultar su falta de competitividad en los mercados internacionales. Una vez más se prueba que la situación de hegemonía militar, al no ir de consuno con otra industrial y comercial, no puede ejercerse como tal y sólo es válida en un contexto de respeto a la multipolaridad real que hay en el mundo (21), ¿O verdaderamente es creíble que los EEUU desencadenarán ahora una guerra como las del siglo pasado contra Japón o la Comunidad Europea por el control de los mercados mundiales?

Pues, cuando de mercados se trata, la situación se hace delicada. Más abajo, en la secciọn de problemas políticos, hablaremos de las dificultades que plantea el orden comercial mundial y la estructura organizativa que lo ampara a través del GATT. Ahora cabe observar cómo los Estados Unidos muestran una tendencia a razonar de forma tan interesada en lo referente al comercio mundial como en su día lo hicieron aquellos teóricos de la dependencia, quienes trataban de culpar a los países desarrollados del subdesarrollo de los otros mediante la teoría de los intercambios desiguales (22) cuyo núcleo era que los mercados internacionales no se rigen por las condiciones ideales de la ley de la oferta y la demanda, sino que están mediatizados por consideraciones extraeconómicas, normalmente de poder político o de otro tipo, lo que falsea la normal formación de los precios en detrimento de los menos favorecidos (23). Hoy, cuando la teoría de la dependencia está prácticamente desechada, los EEUU aducen razones de índole extraeconómica para 
justificar tanto su pérdida de competitividad en las relaciones bilaterales con el Japón, como su progresiva pérdida de cuota de mercado mundial frente a éste, la Comunidad Europea o, incluso, los países recientemente industrializados del Este y el Sureste asiático.

En las condiciones antedichas queda claro que, no siendo posible hoy día recurrir a la política de la cañonera en las relaciones económicas y comerciales internacionales, la unipolaridad estadounidense se ve obligada a coexistir con una multipolaridad real y de hecho que condiciona su acción.

\section{PROBLEHAS MORALES}

En el delicado terreno de los principios morales y la seguridad jurídica internacionales, la cuestión que se plantea es la de si se puede aceptar una situación de unipolaridad o hegemonía de una potencia en un mundo en que el principio de soberanía estatal compartido por todos ordena atender a los intereses propios a la hora de orientar la acción. De nuevo se trata de un problema de Realpolitik. Es decir, ¿por qué ha de suponerse que, a la hora de actuar en un conflicto determinado, los EEUU hayan de regirse por principios desinteresados y éticos en lugar de dar preferencia a los intereses propios?

A tenor con lo expuesto más arriba (24) el final de la guerra fría implica también el del comunismo y, con éste, de las concepciones políticas autoritarias y totalitarias. Es decir, implica la posibilidad por primera vez en la historia de la universalización de la democracia (25). A su vez, desde los tiempos de Tocqueville venimos identificando a los Estados Unidos con la democracia (26) y, por lo tanto, nọ podrá extrañarnos que, en principio, en el ámbito moral, ésta resulte ser la era americana.

En consecuencia, de encontrarnos en el mejor de los mundos, pudiera pensarse que finalmente aquella universalización de la democracia daba contenido y enjundia a la famosa fórmula constitutiva de la identidad yanqui del Manifest Destiny (27). Al fin y al cabo, mientras duró la bipolaridad, frente a la pretensión enarbolada por la Unión Soviética de ser el faro de la revolución mundial y el centro de la expansión planetaria del comunismo, sólo se alzaba la simétrica estadounidense de ser el foco de la extensión de la democracia.

Algo de esto cabe atisbar ya hoy, aunque sea de forma algo incierta. Basta para ello con estùdiar las reacciones actuales de la opinión pública mundial ante los últimos actos de intervencionismo yanqui en el continente americano desde 
la década de los 80. Y considerar también las diferencias evidentes en unos y otros actos de intervención. Resulta evidente que no ha sido lo mismo el apoyo a la contra nicaragüense que la invasión de Granada (ambos actos durante la presidencia de Reagan) o que la invasión de Panamá y la detención de Noriega. Si, por un lado, cabe suponer una mayor atención de la administración norteamericana a la opinión pública mundial en su acción exterior en el continente, como se prueba en el caso de Nicaragua (28), por otro se detecta una mayor predisposición de esa misma opinión pública a reconocer a los estadounidenses una competencia de gendarme en la zona y a hacerse cargo también de los argumentos de éstos en contra de la subversión (29). El caso de Panamá, por último, permitirá ver con nitidez esta cuestión. Es claro que, internacionalmente, no hubo mayores protestas cuando los estadounidenses invadieron el país y se llevaron detenido al General Noriega y, en todo caso, las pocas protestas que hubo se refirieron más a la contundencia de la acción que al hecho de que alguien dude de que el citado general vaya o no'a tener un juicio justo en los EEUU. Este consenso incipiente, sin embargo, podría romperse si, al final de este decenio, viniera a resultar que la invasión de Panamá sólo trataba de encontrar una excusa para no dar cumplimiento a las previsienes del Tratado Carter-Torrijos de devolución del cánal (30). Es decir, el asunto que aquí se ventila no es el de la mayor o menor confianza de lá opinión mundial en la sinceridad de los norteamericanos en su Manifest Destiny, sino la conveniencia de arbitrar un marco jurídico internacional, aceptado por todos y con eficacia directa, que haga innecesarios los riesgos de la confianza y la intención de los actores. Entre otras cosas, porque la aceptación de ese marco normativo de derecho internacional es, en efecto, la mejor prueba posible de que hay en marcha un proceso de moralización de las relaciones internacionales (31).

La cuestión de la aceptación por todos (pero, muy especialmente, por la potencia hegemónica que es la que tiene capacidad para alterar las circunstancias) de un orden jurídico internacional con vertiente judicial es el problema moral primero, del que depende como un apéndìce el-político de cómo dotar de la fuerza necesaria a ese orden jurídico. Hasta la fecha, el comportamiento de los EEUU, como el de todos los países, ha sido ambiguo. Tras una aceptación de principio, se negó a aplicarse la decisión del Tribunal Internacional de La Haya relativa al minado del puerto de Managua (32). Ahora bien, por éntonces todavía era real la bipolaridad y los norteamericanos podían argumentar con la situación de excepcionalidad que siempre supuso la guerra fría. Esta situación ha terminado y ahora se abren nuevas posibilidades. Es cuestión de preguntarnos si darán fruto. 
Al respecto es opinión común que se precisa un cambio de perspectiva si se quiere conseguir la moralización eficaz de las relaciones internacionales. Un asunto hoy accesible por cuanto ha dejado de darse la distorsión sistemática de aquéllas que siempre acarreaba el sistema mundial del comunismo. Dicho en otros términos, hoy día, la propuesta ética en el ámbito internacional afecta a la tendencia de los Estados a seguir criterios de Realpolitik, pero no ya a aquella situación del pasado en que uno de los dos polos consideraba que mejoraban sus intereses cuando se extendía la subversión por los otros países. De hecho es sumamente significativo que hayan sido los mismos soviéticos quienes han propuesto un giro de $180^{\circ}$ en la política internacional a través de lo que en los tiempos de la perestroika llamóse "nueva mentalidad" (33). Esta nueva mentalidad, caso de ser propuesta sincera, significaba un enorme esfuerzo de parte de los comunistas, puesto que venía a ser una paladina confesión de errores en el orden internacional y una aceptación del punto de vista del adversario. Esto es, nada menos que la negación del punto de vista leninista de concebir las relaciones internacionales como un terreno más de la lucha de clases para dejar paso a una concepción que ve a la Humanidad en su conjunto como titular también de unos intereses planetarios. A estos efectos, ha ayudado mucho la repentina materialización de las preocupaciones ecologistas en la ex-Unión Soviética tras la catástrofe de Chernóbyl.

Ahora se requiere averiguar en qué medida están Occidente y, sobre todo, los EEUU, dispuestos a actuar de acuerdo con sus enunciados. Ciertamente, nadie en uso de sus facultades mentales en Occidente niega que las cuestiones ecológicas y de conservación del medio sean transfronterizas y que requieran un centro decisorio mundial capaz de adoptar decisiones antes de que sea demasiado tarde. El problema es pasar de esa aceptación sin más a una situación en que se adopten las medidas oportunas. El Presidente Bush, por ejemplo, al negarse a adoptar decisiones a la vista del problema del ozono en tanto no haya estudios científicos más concluyentes (34) puede ser, en efecto, un gobernante sabio y prudente, que no se precipita a malgastar recursos ante un mero rumor, o puede ser un necio insensible que está jugando con el destino de la humanidad de modo irresponsable. En cualquiera de los dos casos, parece evidente que, a la hora de acometer los problemas generales, la Humanidad no puede depender del juicio de una sola persona, por esclarecida y bien asesorada que esté, sino que se requiere un orden internacional y objetivo de adopción de decisiones a escala planetaria. Lo cual nos lleva a la consideración de la multipolaridad concreta y real que se da en la esfera ínternacional, en el entramado de los aspectos políticos, militares. jurídicos y económicos. 


\section{PROBLEMAS POLITICOS}

Es en el terreno de las organizaciones prácticas, reales, con actuación en la esfera internacional, donde con mayor claridad puede verse la contradictoria naturaleza del orden internacional que se viene considerando en este trabajo, esto es, la de ser un orden formalmente unipolar y materialmente multipolar. Por supuesto que la sociedad internacional está cruzada hoy por una enorme variedad de organizaciones y que fuera tarea tan inútil como prolija mencionarlas a todas y, mucho más, pretender que todas ellas tienen un grado de eficacia parangonable, cada una en su ámbito. Necesidades de espacio, así como conveniencias de la estructura de la exposición nos obligan a concentrar nuestra atención en aquellas organizaciones que, a nuestro juicio, tienen auténtica importancia en el orden internacional y ayudan a entender el planteamiento que aquí se está haciendo. Tales organizaciones son distintas por su objetivo, carácter, alcance y ámbito territorial. Son el Grupo de los Siete países más industrializados, la ONU, la OTAN, el GATT, la Conferencia sobre Seguridad y Cooperación en Europa (CSCE) y la Unión Europea (UE) (35). EI elemento esencial a los efectos de este trabajo y que las unifica es que los EEUU pertenecen a todas, al igual que Gran Bretaña, Francia, Alemania, Holanda e Italia. Por lo demás, hay razones para incluir a la UE, a pesar de tratarse de una organización regional. No se quiere con ello hacer de menos organizaciones como la OEA o la OUA, pero habrá de admitirse, a fuer de realista, que la UE sólo es regional en un sentido territorial, no político ni económico.

\section{EI Grupo de los siete paises más industrializados (G7)}

No es exagerado considerarlo como una especie de comité decisorio de la OCDE y como el verdadero gobierno en sentido informal del conjunto de los países occidentales. Las reuniones en la cumbre de estos siete países (EEUU, Canadá, Gran Bretaña, Francia, Alemania, Italia y el Japón, a los que posteriormente se uniría el Presidente de la Comisión Europea) comenzaron a mediados de los años setenta y por entonces trataban de formular una política económica común de los países de la OCDE frente a los problemas planteados a partir de la guerra del Yom Kippur y de la repentina alza de los precios del petróleo. Posteriormente pasaron a coordinar otros tipos de políticas, no solamente las económicas y cada vez han ido ampliando más el campo de sus actividades y preocupaciones. En la actualidad, el G7 también trata de establecer una actitud común en relación con terceros países, muy especialmente los antiguos estados socialistas y también los del Tercer Mundo. 
Tamames cree que el grupo debiera dar entrada en su seno a estos dos grupos de intereses (36), llamados "del Este" y "del Sur", pero, en tal caso, es difícil que el organismo pudiera seguir llamándose de los países "más industrializados"; y, si hubiera de aumentar su composición, en verdad, no está claro porqué no habría de hacerlo en el seno de la ONU.

Ciertamente, el G7 aparece aquejado de un claro déficit de legitimidad en el mundo contemporáneo. Desde un punto de vista de pura Realpolitik, ya reiterado en este trabajo, el G7 es el órgano más importante de mando en el ámbito internacional dado, sobre todo, que controla a las dos instituciones internacionales más importantes en el orden financiero, esto es, el Banco Mundial y el Fondo Monetario Internacional. Por medio de estos dos órganos, el G7 determina la prosperidad o la ruina de las naciones a base de imponerles determinados recetarios de desarrollo económico considerados "ortodoxos" desde el punto de vista de la teoría económica. Por todo ello, el G7 es un órgano poderoso. Sin embargo, cuando se toman en consideración aspectos morales, no pasa de ser una especie de boceto de gobierno oligárquico, contrario al espíritu democrático de la contemporaneidad. De poder superarse ese déficit de legitimidad, dicho se está, habría de ser en el marco de la ONU.

\section{La ONU}

Se trata de la organización internacional más importante. Sucesora de la Sociedad de Naciones, que tuvo su momento en el período de la entreguerra, ha sido la que más ha acusado el impacto de los vertiginosos cambios de los últimos años. De hecho, la mudanza habida en la política exterior de la antigua Unión Soviética, configurada en la sedicente "nueva mentalidad", ha permitido que la ONU haya superado su tradicional inoperancia y haya comenzado a resultar eficaz, como puede verse en la solución del problema de Namibia, la pacificación de Angola $y$; más recientemente, el acuerdo de Camboya. No obstante, para muchos, las Naciones Unidas han mostrado su principal punto débil en la Guerra del Golfo donde, siempre según los críticos, han ido a remolque de las decisiones adoptadas por los Estados Unidos y han servido para justificarlas (37). Desde luego, esta impresión se produce porque el orden mundial ha pasado de la bipolaridad a la unipolaridad. Lo cual implica dos cosas: en primer lugar, que la ONU fue imprescindible, aunque sólo fuera como foro de debate, no de adopción de decisiones, en tiempos del enfrentamiento de la guerra fría. En segundo término que si la ONU 
aspira a seguir cumpliendo una función en nuestro mundo, tendrá que proceder a una reforma estructural.

Ahora bien, esta reforma estructural de la Carta de la organizacion aparece condicionada por dos circunstancias. La primera es la composición del Consejo de Seguridad y la segunda, la relación entre el tal Consejo y la Asamblea General. Respecto al Consejo de Seguridad, es evidente que su composición ya no refleja la realidad del mundo contemporáneo. La permanencia en él de la antigua Unión Soviética (todavía sin nombre en el momento de redactar este trabajo) no es menos llamativa que la ausencia de dos vencidos en la Segunda Guerra Mundial pero que en el mundo actual son dos potencias económicas, Alemania y el Japón. Sin duda, la exclusión de un país de este órgano es asunto más difícil que la posible inclusión de otros o de organizaciones, a su vez. Por ejemplo, parece razonable que Francia e Inglaterra hablen en nombre de la Comunidad Europea, ya que ésta pretende tener una política exterior única; lo cual, además, podría ser un gesto en el sentido de resolver el problema de Alemania, pero no el del Japón. En cualquier caso será difícil acometer una reforma del Consejo de Seguridad sin pasar por la aprobación de la Asamblea General y, además, se puede bloquear mediante el uso del veto en el primero.

En cuanto a la Asamblea General es evidente que su composición ultrademocrática no es razonable. El mantenimiento del absurdo de que Benin, por ejemplo, tenga un voto, igual que los Estados Unidos es, en parte, el responsable de que sea necesaria luego la existencia de un órgano como el Consejo de Seguridad, que desvirtúa la posible obra de la Asamblea. Una solución intermedia, que permitiría avanzar por la vía de convertir a la ONU en un auténtico gobierno mundial, fuera la ponderación del voto en la Asamblea en un sentido parecido al del Consejo de la UE, sin que ello suponga prejuzgar las dificultades inherentes a este plan y que son muchas. En el Consejo, los países tienen una cantidad de votos proporcional a su población; es evidente que en el caso de la Asamblea General de las Naciones Unidas habría que encontrar un criterio múltiple que no solamente tuviera en cuenta la población sino la extensión territorial y el PIB cuando menos.

Otra carencia evidente en la Organización de las Naciones Unidas es la de una fuerza coactiva propia. El mecanismo actual por el cual la ONU cuenta con tropas puestas a su disposición por los Estados miembros es claramente insatisfactorio.

Quizá pueda remediarse ésta hoy contando para ello con el bloque militar defensivo más importante de nuestro tiempo, es decir, buscando una mane- 
ra de vincular orgánicamente a la ONU con la OTAN, para lo cual también sería necesario reformar ésta.

\section{La OTAN}

El surgimiento de la OTAN en 1949 está indisolublemente ligado a la guerra fría y al enfrentamiento con el bloque de los países del Este de Europa, agrupados luego en el Pacto de Varsovia. La situación internacional ha cambiado desde entonces en tal medida que ya no hay países del Este (en el sentido político) ni Pacto de Varsovia; razón por la cual muchos (sobre todo entre los viejos pacifistas o entre quienes sin serlo del todo, alardeaban de pacifismo para fomentar los intereses del llamado "movimiento comunista") han pedido reiteradamente la disolución de la OTAN (38) por considerarla una amenaza para la paz mundial. Es evidente, sin embargo, que la OTAN, de haber sido amenaza para esa paz, no ha pasado de la amenaza. La OTAN no ha invadido territorio de ninguno de sus miembros (como sí hizo el Pacto de Varsovia) y no se ha visto involucrada en ningún conflicto con terceros países.

La OTAN es el bloque militar más duradero y que mejor ha garanti84 zado la seguridad de sus miembros. Ahora, que muchos países ex-socialistas (incluida la ex-Unión Soviética) han mostrado estar interesados en ingresar en ella, la funcionalidad de la organización ha quedado de manifiesto. Con esta reflexión no se pretende conseguir que quienes han sostenido contra toda evidencia que la OTAN era un foco de agresión, de inestabilidad y de peligro para la paz mundial cambien de opinión, pues este tipo de razonamientos suelen encontrar su rạzón de ser allende sus planteamientos concretos, pero sí que no se alcancen cotas insólitas de marrullería política. Tal cosa sucede cuando se argumenta que, habiéndose disuelto el Pacto de Varsovia (como si los rusos lo hubieran permitido por su amor a la paz mundial), bien pudiera hacer lo mismo la OTAN y, caso de no ser así, quedará clara la finalidad belicista de la organización.

Ahora bien, no es posible olvidar que la OTAN tiene un ámbito de acción geográficamente determinado al Atlántico Norte. En la actualidad, ese ámbito de acción se ha quedado angosto y, de hecho, la organización tendrá que actuar en otras latitudes. Para ello sería conveniente que incorporara a otros países representativos que dieran a la Organización un mayor alcance, cosa que puede hacerse hoy sin abandonar su postulado de incluir solamente a regímenes democráticos y valiéndose para ello también de la red de los pactos defensivos de los EEUU. 
Caso de hacerse así quizá pudiera configurarse la OTAN como el brazo armado de las Naciones Unidas.

\section{GATT}

El Acuerdo General sobre Tarifas y Comercio (GATT) es una de las piezas esenciales del orden internacional de la postguerra y que ha ido aumentando en importancia progresivamente a medida que iba viéndose cómo, en este último, las relaciones más importantes y más potencialmente conflictivas eran las mercantiles. De hecho, en la actualidad, cuando no está claro que pueda salir adelante la Ronda Uruguay, imprescindible sin embargo para la normalización del comercio internacional, las distintas partes coinciden en un solo punto, esto es, que no podemos permitirnos el lujo de prescindir del GATT si no queremos una guerra comercial mundial que traiga consigo una recesión económica y acaso cosas peores. Para nadie es un secreto que buena medida de la crisis de recesión por la que atraviesan los Estados Unidos de hoy tiene su origen en ữnas relaciones comerciales deficitarias con el Japón que están en la base de una actitud de permanente recrimịnación estadounidense respecto a las supuestas prácticas restrictivas japonesas en los intercambios comerciales (39).

A diferencia de las organizaciones citadas hasta ahora, el GATT no requiere reforma alguna de importancia. Bastará solamente con que las partes se pongan de acuerdo respecto a su funcionalidad. Y ésta no se agota en la garantía del comercio mundial. Al contrario, también despeja el camino para el buen quehacer de otras instancias. Por ejemplo, es evidente que solo el respeto escrupuloso a los requisitos del GATT puede conseguir que se normalicen las relaciones comerciales entre la UE y los Estados Unidos y que éstos no puedan acusar a la primera de intentar convertirse en una "fortaleza Europa". A la inversa, también Europa habrá de conseguir las concesiones necesarias de los estadounidenses de forma que los productos europeos resulten competitivos en los mercados norteamericanos.

En definitiva, la necesidad del GATT resulta cada vez mayor a la vista de los continuos e imparables procesos de integración económica en todo el planeta, desde el tratado de libre comercio entre los Estados Unidos y México hasta el área económica del Pacífico encabezada por el Japón y en la que puede incluirse un mercado tan inmenso como el chino. 


\section{B. La Conferencia de Beguridad y Cooperación en Furopa (CSCE)}

No se trata aquí de una organización internacional en el sentido ordinario del término, sino de una Conferencia que ha ido institucionalizándose de un modo paulatino. Su importancia, sin embargo, para los acontecimientos decisivos en la historia más reciente de Europa no se puede exagerar. En buena medida gracias a ella ha sido posible la evolución de los países del Este y Centro de Europa que ha acabado en la crisis final del comunismo (40). Así, por ejemplo, ha sido en la CSCE donde se ha sentado la doctrina del derecho internacional de fiscalización sobre los derechos humanos en los Estados, doctrina revolucionaria que ha roto el principio de no injerencia en los asuntos internos de otros países, que era lo habitualmente invocado en estos casos y que permitió que se organizara la oposición en los países socialistas a partir de 1975.

La CSCE, que reúne a todos los países europeos así como a los Estados Unidos y Canadá, es un foro adecuado a fin de plantear problemas de aleance europeo y debatirlos, pero no ha resultado ser un órgano útil para imponer soluciones a los conflictos. Al respecto, la CSCE es, en parte, víctima de la situación de desconcierto mundial, al no haber respaldo de coacción física para imponer criterios de carácter moral o simplemente políticos. Por ejemplo, ni la "carta de París", de noviembre de 1990, ni el "Comité de Prevención de Conflictos" han conseguido detener la guerra civil yugoslava. De aquí se sigue que la CSCE, capaz de poner en marcha un proceso de dimensiones y consecuencias históricas, no está en situación de encauzarlo después. En parte ha sido víctima del fracaso de alguna formulación política que aparecía inás claramente vinculada a ella, como la de la "casa común europea" (41).

La CSCE puede ser el marco en el que se acabe reorganizando el continente europeo, pues tiene legitimidad sobrada para ello gracias, en realidad, a que no habiendo hecho nada concreto desde mediados de los años ochenta, conserva el respeto generalizado y toda la potencialidad a que se hizo acreedora gracias a sus buenos resultados en los años setenta. Ahora bien, para llevar a efecto esta tarea de convertirse en una especie de foro paneuropeo con presencia de los norteamericanos deberá coordinar su acción, a su vez, con la Unión Europea.

\section{La Untón Europea (UE)}

La antigua Comunidad Europea se encuentra en un proceso de mayor integración que, quizá no llegue nunca a funcionar como un verdadero Estado tradicional. Ello no impide que sea la principal potencia comercial del mundo y el 
modelo reducido de cómo podría funcionar un gobierno mundial, del que todos hablan pero que nadie sabe cómo articular.

De hecho, un análisis sucinto de ese delicado equilibrio que es la UE debe considerar cuatro planos distintos: a) el interno; b) las relaciones con el resto de Europa; c) las relaciones con los antiguos imperios; d) las relaciones con los Estados Unidos y el Japón.

\section{a) El plano interno}

Es difícil que los doce países de la UE (que pueden ser más en un plazo relativamente breve) lleguen a conseguir una integración política superior a la que establecieron en el Consejo de Maastricht, de diciembre de 1991. Con todos los respetos a los viejos federalistas, partidarios de los Estados Unidos de Europa, cabe también preguntarse si tal integración fuera conveniente o necesaria. En una época de mayores tendencias al autogobierno de los entes territoriales menores, subestatales, regionales, es evidente que habrá fuertes resistencias a la idea de generar un poder político centralizado único en un ámbito tan variado y plural como el continente europeo. Mucho más sensato parece ser éncontrar una fórmula aceptable de división de los poderes entre las diversas instancias y satisfactoria para todas ellas. La UE lo es ahora y es dudoso que pudiera serlo más y conservar al mismo tiempo ese delicado equilibrio entre la vocación políticamente integradora y la conveniencia de incluir en ella a una cantidad mayor de países del continente. En dos palabras: carece de sentido hablar de una Unión Europea que deje fuera a Austria, Checoslovaquia, Suecia, Polonia, Suiza, etc.; por otro lado, resultará imposible hablar de una posible integración de Austria, Checoslovaquia, etc., en - una estructura estatal cerrada.

b) Las relaciones con el resto de Europa

La UE no puede vivir de espaldas a su continente. Ahora bien, dentro de éste y fuera de ella quedan dos tipos de países: los de la antigua Asociación Europea de Libre Cambio (AELC), con los que ya tiene un acuerdo preferente (razón por la que nos' permitimos llamarla "antigua") y los del antiguo Consejo de Ayuda Mutua Económica (CAME). Y conviene distinguir con cuidado entre ambos grupos. Mientras que los de la AELC son países que pueden ingresar en breve tiempo en la UE por compartir con ésta los sistemas político y económico, así como las pautas civilizatorias, los del ex-CAME sólo comparten de momento ( $y$ no por entero) el sistema político; el económico está aún en estado de transición; y respecto a las pautas civilizatorias, si bien son básicamente las mismas que las de la UE, el medio siglo de régimen comunista ha dejado un poso extraño cuyas manifestaciones 
en las circunstancias nuevas todavía ignoramos. Todo ello implica que su posible integración en la UE será más problemática. En especial por las grandes disparidades económicas. En términos más claros, los países del ex-CAME, con la excepción de Alemania del Este y, quizá, de Checoslovaquia, requieren urgente y masiva ayuda financiera de la UE si quieren reparar sus infraestructuras, contrarrestar la catástrofe ecológica y reponer su capacidad productiva (42). De no recibirla y pronto se enfrentan a una situación de caos social imprevisible y, seguramente, de emigración en bloque. Probablemente puede sostenerse que la UE tiene un deber moral de ayudar a estos países, mezclado también con puras consideraciones egoístas de supervivencia (ayudar para evítar la inundación de inmigrantes procedentes del Este y Centro de Europa. Pero no parece que quepa hacer frente a tales obligaciones (si son tales) con independencia de lo que sea preciso hacer en otras partes del mundo, por ejemplo, en los antiguos imperios y zonas de influencia.

c) Las relaciones con los antiguos imperios

En gran medida estamos hablando aquí de lo que convencionalmente conocemos como Tercer Mundo, esto es, algo con lo que es preciso contar en todo estudio sobre el Nuevo Orden Mundial. Vale para él lo dicho también en el epígrafe anterior respecto a los antiguos países socialistas, es decir, los del primer mundo deben aceptar una responsabilidad moral para subvenir a su desarrollo económico que aparece también imbricada con una consideración de autoconservación en la medida en que dicha ayuda (que habrá de ser además real y no puramente ficticia o simbólica, como ha venido siendo la Ayuda Oficial al Desarrollo) permita que los países puedan desenvolverse económicamente y retengan a su población. Para ello, es evidente, será necesario concentrar este mecanismo de ayuda en alguna instancia internacional eficaz al efecto lo que significará dos cosas: primera, que los beneficiarios habrán de aceptar mermas en el concepto tradicional de soberanía; segunda, que los beneficiantes se pongan de acuerdo para no aprovecharse indebidamente de la política de ayuda. 
1. La bibliografía al respecto empieza a ser ya abundante. Una de las últimas y más interesantes obras es Jacques Lesourne y Bernard Lecomte Después del comunismo, Arias Montano, editor, Madrid, 1991.

2. Casi todos los estudios solure la perestroika evidencian este aspecto: la Unión Soviética era una ruina y una catástrofe económica. Micher Heller, El séptimo secretario, Esplendor y miseria de Mijail Gorbachov, Ediciones de la Tempestad, Barcelona, 1991. Pero no solamente las obras publicadas por los autores occidentales: también las escritas en la URSS. Empezando por la Perestroika, de Mijail Gorbachov, Ediciones B, Barcelona, 1987, donde reconoce el fracaso económico no del socialismo en su conjunto, sino de la llamada "economía de ordeno y mando", como si ésta no fuera consubstancial al socialismo marxista, y proponiendo también la construcción de un vagoroso "socialismo de mercado", en expresión que luego haría fortuna en Europa Occidental. Y también los economistas soviéticos han dicho algo al respecto. Abel Aganbegyan (La perestroika económica, Grijalbo, Barcelona, 1989), aunque muy apologético con la perestroika y vacuamente oficialista, deja entrever lo desesperado de la situāción. Entre las obras más recientes, que no deja lugar a dudas solıre el hundimiento económico del comunismo, como "erisis general del comunismo", véase Vladimir Boukovsky, La Unión Soviética, de la utopía al desastre, Arias Montano, Editor, Madrid, 1991.

3. Las obras más recientes, vinculadas a esta cuestión y con mayor conocimiento de causa son las de Hélène Carrere D'Encause, véase, por ejemplo, El triunfo de las nacionalidades. El fin del imperio soviético, Rialp, Madrid, 1991. También hay observaciones interesantes en Fernando Luengo, "El problema nacional", en Carlos Taibo (Comp.), De la revolución de octubre a Gorbachov. Una aproximación a la Unión Soviética, Fundamentos, Madrid, 1991.

4. En otro lugar he analizado el comunismo de la URSS como un resultado de esta oposición entre lo ideológico-ficticio y lo real. V. Ramón Cotarelo, "La desintegración de la URSS", Diario 16, 1-12-1991 y "El mito del comunismo soviético", Diario 16, 8-12-1991.

5. Y también en pocos lugares se verá más claramente cómo Stalin era fiel continuador de Lenin. El libro canónico en la URSS era J. Stalin, La cuestión nacional, que refleja fielmente el sentir leninista. No cabe admitir aquí la intención de la historiografía soviética posterior de establecer una distinción entre Lenin y Stalin.

6. El esfuerzo y meritoria actitud de oposición se transparenta en las abundantes páginas de una autobiografia de señalado interés, como la de Andrei Sajarov, Memorias, Plaza y Janés/Cambio 16, Barcelona, 1991. Ya teníamos cumplida noticia, por lo demás, de la labor de zapa de la oposición en algunos textos "clásicos", como Fernando Claudín, La oposición en el "socialismo real", Siglo XXI, Madrid, 1981.

7. Tómense, por ejemplo, las cifras del PIB para 1991 en paises relativamente comparables: España: $\mathbf{5 1 0 . 0 0 0 ~ m i l l o n e s ~ d e ~ d o ́ l a - ~}$ res; Polonia: 112.900 millones de dólares (la 5 parte); Austria: 172.000 millones de dólares; Hungría: 44.100 millones de dólares (la $4^{\mathrm{b}}$ parte); Dinamarca: 135.000 millones de dólares; Checoslovaquia: 52.200 (entre la mitad y la tercera parte, con tres veces más población). V. The Economist, The World in 1992, Londres, diciembre de 1991.

8. La inflación es hoy galopante. En 1990, las cifras fueron: Checoslovaquia, el $14 \%$; Hungría, el 29\%; Bulgaria, el 50\%; Rumanía, el 20\%; URSS, el 10\%; Yugoslavia, el 550\% y Polonia el 800\% (v. Der Spiegel, $n^{\circ}$ 17, año 45, 22 de abril de 1991). Para el año de 1991, en algunos lugares empeoraron y en otros mejoraron; pero siempre fueron muy altas: Checoslovaquia, 60\%; Hungría, del 36\%; Polonia, el 64\%; Unión Soviética, $150 \%$ (v. The Economist, The World in 1992, cit.). En cuanto al descenso de la producción industrial, las cifras son también significativas. Por lo que hace al año de 1990 , son las siguientes: Checoslovaquia, $\mathbf{- 3 \%}$; Hungría, -5\%; Bulgaria, -11\%; Rumania, -12\%; URSS, $-4 \%$; Yugoslavia, $-10 \%$; Polonia, $-12 \%$ (v. Der Spiegel, cil.). 
9. En la URSS, por ejemplo, "de acuerdo con una estimación calificala de conservadora, más de la mitad del agua de consumo doméstico e industrial está contaminada", Carlos Taibo, La Unión Soviética de Gorbachov, Fundamentos, Madrid 1989.

10. De hecho, una de las primeras cosas que hacen las repúblicas rebeldes en la ex-URSS es recabar pleno dominio sobre sus riquezas y recursos naturales. Por ejemplo, en el verano de 1991, y antes de la recolección, los ukranianos, que ya estaban en un sendero independentista, pensahan en erigir aduanas con el resto de las repúblicas de la Unión, para conservar sus bienes. The Economist 20-26 de julio de 1991, pág. 26.

11. Un cuadro comparativo de. las cifras referidas al año de 1988, el último añ்o tranquilo del CAME, el Pacto de Varsovia y la RDA, es decir, antes de que empezara el éxodo de 1989 que condujo a la caída del muro de Berlín en noviembre de ese año.

\begin{tabular}{llcr} 
& $\begin{array}{c}\text { Esperanza } \\
\text { de vida }\end{array}$ & $\begin{array}{c}\text { Mort. inf. } \\
(0 / 00)\end{array}$ & $\begin{array}{r}\text { PIIJ/hJut. } \\
\text { S EEUU }\end{array}$ \\
\hline Alhania & 70 & 43 & 776 \\
Bulgaria & 71 & 16 & 5.898 \\
Cher:oslovaquia & 70 & 15 & 7.604 \\
Hungría & 71 & 20 & 2.240 \\
Polonia & 72 & 18 & 1.930 \\
RDA & 69,5 & 9 & 11.400 \\
Rumanía & 72 & 24 & 1.666 \\
URSS & 70 & 25 & 6.160 \\
Yugoslavia & 72 & 27 & 2.480 \\
\hline Meelia de Países & & & \\
del Este & 70,8 & 21,8 & 4.105 \\
\hline Media de Países & & & \\
ile la CE & 75,4 & 10,5 & 10.211 \\
España & 76 & 10 & 6.010
\end{tabular}

FUCNTE: elaboración propia a partir de los datos del Fischer Weltalmanach, 90, Fischer, Frankfurt, 1989.

12. Llevamos varios años asistiendo a la polémica sobre las enseñanzas del hundimiento del comunismo y hay actitudes para todos los gustos. Una muy extendida entre los militantes e intelectuales comunistas es que lo que ha fracasado no ha sido la teoría, sino su apli- cación práctica. Véanse como muestra las afirmaciones de Rafael Ribó, secretario general del PSUC, miembro del CC. del PCE y profesor de Teoría del Estado, en el XIII Congreso del PCE en Madrid, el 20-12-91, en las que reconoce el fracaso del modelo "socialismo real" y la contestación de Julio Anguita en el mismo congreso, afirmando que eso afectaría al PCUS, pero no al PCE, que se había independizado de aquél. V. Diario 16, 22-12-91. Por lo demás, las versiones pueden ser muy distintas y extremas. Por ejemplo, la organización Unidad Comunista de España cree que el hundimiento de la URSS es, en realidad, el de una forma de fascismo. "Fascismo es la dictadura terrorista del capital monopolista. Fascismo es el régimen policíaco y de terror con que la burguesía soviétiva ha sojuzgado al pueblo de las nacionalidades de la URSS". V. De Verdad, semanario de Unificación Comunista de España, $n^{2}$ 8, Madrid, $1^{\text {a }}$ quincena de octubre de 1991, pág. 14.

13. Un señalar este con diversas finalidades. Hay quien lo pone de manifiesto como una ventaja y un beneficio del mundo contemporáneo, en un punto de vista muy cercano al de este artículo. V. Manuel Pastor, "De la guerra fría a la unipolaridad", El Siglo, n" 5 , Madrid, 18-11-1991, y quien lo denuncia con mayor a menor intensidad. Por ejemplo, Ramón Tamames, Un nuevo orden mundial, Espasa-Calpe, Madrid, 1991, quien habla de un "segundo siglo americano" (p. 159) si bien en términos críticos y coincidiendo con otras opiniones, según las cuales, la hegemonía internacional estadounidense acaba absorbiendo recursos financieros de las zonas más desfavorecidas del planeta, importando capitales compensadores de su déficit comercial. V. Manuel Gala, "El orden económico internacional", Sistema, $\mathrm{n}^{2}$ 102, Madrid, mayo de 1991, pág. 12.

14. No cabe duda de que la época de guerra fría, a la que ha puesto fin la pax americana se ha caracterizado por un elemento componente de intenso contenido ideológico. Al haberse resuelto, y en favor de uno de los bandos contendientes, resulta lógico que las ideas por las que ese bando ha luchado se consideren victoriosas. La interpretación según la 
cual la derrota del comunismo frente al capitalismo no significa la victoria del capitalismo es algo asombroso. "... si bien es cierto que desde una perspectiva histórica hemos sido testigos de la crisis del comunismo, no es menos cierto que el intento neoliberal de los años setenta y ochenta no ha dejado apenas un elemento de realización positiva que permita augurar su continuidad en los años noventa". V. Alfonso Guerra, "Socialismo y economía", en El socialismo del futuro, $\mathrm{n}^{\circ} 3$, Madrid, 1991, pág. 4.

15. Según la Oficina Presupuestaria del Congreso de los EEUU, los costes directos de la guerra estarían entre 40.000 y 45.000 millones de dólares; dado que tenía comprometidos $\mathbf{5 3 . 5 0 0}$ millones con los aliados, el país podría estar haciendo un negocio con la Guerra del Golfo. V. "A Nice Little Earner", en The Economist, 9-15 de marzo de 1991.

16. Uno de los libros más recientes en este terreno de la producción bibliográfica decadentista es el de Paul Kennedy, Auge $y$ caída de los imperios, Plaza y Janés/Cambio 16, Barcelona, 1989.

17. John Naisbitt y Patricia Aburdene, Megatrends 2000. Las grandes nuevas tendencias para la década de los 90, Plaza y Janés/Cambion 16, Barcelona, 1990, pág. 246.

18. Mucho se lia aireado el intento de un ex-dirigente del Ku-ldux-klan de hacerse con el gobierno de Luisiana. La relativa decadencia estadounidense, en la medida en que sea vivida como una crisis nacional, sin duda aumentará las tentaciones autoritarias, siempre latentes en las demoeracias. Indudablemente un hipotético triunfo de algo parecido al fascismo en los Estados Unidos (incluso eso que algunos llaman el friendly fascism), cambiaría notablemente el escenario internacional pero, hoy por hoy, carece de sentido lucubrar sobre tal eventualidad.

19. El presupuesto de 1991-1992 ya incorpora un déficit calculado en 350.000 a 360.000 millones de dólares, The Economist, 2-8 de noviemhre de 1991, pág. 44. A comienzos de 1991, el total de la deuda de los grandes países Iatinoamericanos (México, Colombia, Venezuela, Brasil, Argentina y Chile, era de unos
273.000 millones de dólares; v. The Economist, The World in 1991, Londres, 1990.

20. Esta situación persistente en los últimos años y que ya ha empezado a afectar también a la UE, ha dado lugar tanto en los Estados Unidos como en la Unión Europea a una nueva moda de Japan bashing, consistente, en lo esencial, en echar a los japoneses la culpa de prácticamente todos los males propios, véase el relato de todas las triquiñuelas que los fabricantes y gohiernos occidentales ponen en el camino de una de los coches japoneses, uno de de los productos más temidos en nuestros mercados en The Economist, 6-12 de julio de 1991, pág. 64.

21. Lo que todo el mundo ha celebrado como un éxito de la diplomacia de George Bush al poner en pie un frente internacional unitario contra lrak en la Guerra del Golfo también puede entenderse más apropiadamente como un hacer de necesidad virtud. Por razones económicas, los Estados Unidos no pueden ejercer solos de gendarme mundial, pues precisan del auxilio y concurso de la comunidad internacional. La Guerra del Golfo sobreviene precisamente cuando el Parlamento norteamericano está aplicando una política de restricción del gasto militar, en concreto, eliminando los créditos destinados a la construcción del bombardero B 2 y reduciendo los efectivos del ejército en $\mathbf{1 4 0 . 0 0 0}$ V. Pierre M. Gallois, "La más extraña de las crisis mundiales", on Política Exterior, Europa ante la crisis, 1990-1991, vol. IV, $\mathrm{n}^{2}$ 18, Madrid, 1990.

22. Originariamente, la teoría comienza como una del neocolonialismo, según la cual, "la colonia anterior sigue siendo un apéndice económico y social de la antigua nación imperialista y con una estruetura socio-económica totalmente dependiente del poder imperialista". Robin Jenkins, Exploitation. The world power structure and the inequality of nations, Macgibbon \& Kee, Londres, 1970, pág. 108. Posteriormente, esta doctrina, más o menos bilateral (ex-colonia/ex-metrópolis) admite mayor complejidad al hacerse multilateral (conjunto de ex-colonias/conjunto de ex-metrópolis o bien periferia/centro). El análisis tiene perspectiva histórica en Immanuel Wallers- 
tein, El moderno sistema mundial, Siglo XXI, Matrid, 1979 y pretende explicar el sentido de La época contemporánea en André GunderFrank, La crisis mundial, vol. 2, El tercer mundo, Bruguera, Barcelona, 1980.

23. Uno de los autores más conocidos y respetados de la teoría, Samir Amin, considera la formación del "capitalismo periférico" como un "desarrollo del subdesarrollo" y cree que en el propio modelo de acumulación del capitalismo contemporáneo se encuentra la explicación de la función que corresponde desempeñar a las economías periféricas, dada la especialización internacional desigual y la necesidad de ajustamiento de la periferia al centro. V. Samir Amin, L'Accumulation à l'échelle mondiale, Unión Génèrule d'Editions, París, 1976, vol. 1, pág. 292 y sigsi.; vol. 2, pág. 302. A su vez, para un análisis en el que intervienen también proyectos de dominación de clase, v. Fernando Henrique Cardoso, Politique et développement dans les sociétés dépendantes, Anthropos, París, 1971.

24. Ver nota 14.

25. Me be ocupado de ello en mi trabajo "La universalidad de la democracia", en Debate abierto, $n^{4} 4$, Madrid, verano de 1991.

26. Esa identificación tosquevilleana (a quien, por cierto, no parecía estorbar en modo alguno la existencia de teaclavos negros) no ha sido cuestionada nunca seriamente. Ni siquiera por los críticos más radicales de la politica norteamericana. Todo lo más que se ha llegado a decir en tiempos de la lucha por los derechos civiles o en contra de la guerra del Vietnam es que los Estados Unidos no eran suficientemente democráticos en el interior (posibilidad que ningún demóorata negará jamás) y tenían una actitud antidemocrátiea en el exterior. V. Noam Chomsky, The Backroom boys, Fontana/Collins, Londres, 1976, págs. 75-77

27. Hablando de la idea de un "imperio americano", que desecha, William Fulbright, sin embargo, reconoce que toca una fibra sensible en el corazón americano. "Recuerda las consignas del pasado acerca de que el disparo de Concord se oiría en todo el mundo, acerca del 'destino manifiesto' y de universalizar la democracia...", J. William Fulbright, The
Arrogance of Power, Penguin, Harmondsworth, 1970, pág. 30.

28. Así se comprieba en las memorias de Reagan, quien deja bien claro que nunca pensó en una intervención directa del tipo de las que los Estados Linidos practicaban aun a mediados de siglo en Centroamérica. V. Ronald Reagan, Una vida americana, Plaza y Janés/Cambio 16, Barcelona, 1991, pág. 504.

29. El cuidado de la opinión pública americana y mundial fue especialmente cluro en el caso de la invasión de esta pequeña isla de $750 \mathrm{~km}^{2}$ y unos 110.000 habitantes, considerada por $R$. Reagan como una amenaza para los Estados Unidos, V. Richard Hart, "Granada: los americanos desembarcan", en VV.AA., El estado del mundo 1984, Ediciones Akal, Madrid, 1983, págs. 518-520.

30. Por ejemplo, Manuel Alcántara, quien considera que la invasión de Panamá fue una "violación del Derecho internacional por parte del gobierno de los Estados Unidos", también dice inmediatumente antes que "Hasta la intervención de las tropas norteamericanas en dieiembre de 1989, su gobierno (el del General Noriega) se desenvolvió entre el autoritarismo y el descrédito y repudio internacional, que había hecho salir a Panamá del Grupo de los Ocho y abandonar el país a numerosos embajadores acreditados". Manuel Alcántara Sáez, Sistemas políticos de América Latina, vol. II, Tecnos, Madrid, 1990, pág. 236.

31. Proceso que, muy adelantado, depende de la evolución de los países de Europa central y oriental. "Las normas éticas determinarán la forma del nuevo orden mundial que está surgiendo. De ahí la importancia de la moralidad y la ética en las relaciones internacionales". V. Robert J. Myers, "La ética en los asuntos internacionales", en Facetas, $\mathrm{n}^{\mathrm{2}} 2$, Washington, 1991. pág. 6.

32. V. Pierre Benoit, "Nicaragua: 1984, el año bisagra", en VV.AA., El estado del mundo 1986, Ediciones Akal, Madrid, 1985, pág. 545.

33. Una prueba de la "nueva manera de pensar" es el informe de Gorbachov presentado en el XXVII Congreso del PCUS, donde se decía que ya no es posible ver la coexistencia pacífica eomo una "forma específica de lucha 
de clases". V. Mijail Gorbachov, Perestroika, Ediciones B, Barcelona, 1987, pág. 135.

34. Desde la izquierda se hu llegado a calificar a Bush por esta actitud de "criminal elimático". Jorge Riechmann, "Nuestra normalidad es la catástrofe. Reflexiones sobre la crisis ecológica global a partir del efecto invernadero", en V.AA., Las transformaciones en el Norte y el Sur del Mundo: entre la crisis y la reestructuración capitalista, Fundación de Investigaciones marxistas, Vol. I, Madrid, 1991 , pág. 69.

35. En un libro reciente Pedro Orive Rivas, al hacer un planteamiento parecido a éste divide los grupos del modo siguiente: "G-2 (EEUU-URSS); G-7 (países poderosos económicamente); G-12 (nuestra CE); G-23 (Asociación Europea de Libre Comercio); G-5 (miembros permanentes del Consejo de Seguridad de la ONU); G-12 (OTAN) y G-35 (CSCE)". Pedro Orive Rivas, Nuevo desorden mundial, Eudema, Madrid, 1991, pág. 65. Dejando al margen que la OTAN no se compone de 12 países ni la Asociación Europea de Libre Comercio de 23, las coincidencias y discoincidencias de ambas clasificaciones son significativas.

36. Ramón Tumames, ob. cit., páğ. 177.

37. "Y puede afirmarse que, en vez de un gobierno mundial, to que sucedió es que el Consejo de Seguridad se convirtió en la caja de resonancia, y en el instrumento legitimador, de las decisiones previamente adoptadas por el Presidente de los EE.UU...". R. Tamames, ob. cit., pág. 284.

38. "Una vez extinguida la organización militar del Pacto de Varsovia, lo lógico sería que desapareciese también la OTAN". José María Laso Prieto, "Las dos Europas: crisis y unificación", en Nuestra Bandera, n" 149, Madrid, II trimestre de 1991, pág. 21. Incluso antes de la disolución formal del Pacto de Varsovia, cuando ya había gobiernos no comunistas ( $y$ hasta anticomunistas en algunos países del Este, en la izquierda española se ahogaba por la salida del país de la OTAN y se argumentaba acerca de la "obsolescencia de los mecanismos de seguridad tanto políticos como militares". V. Carlos Carnero, "Paz y desarme", en VV.AA., El P.C.E. y los retos europeos, P.C.E., Madrid, 1990, pág. 24.
39. La Japan bashing llegó a su máxima expresión recientemente con motivo del 50 aniversario del bombardeo de Pearl Harbour. En 1990, el 33 por cien de los ciudadanos estadounidenses y el 20 por cien de sus dirigentes de opinión consideraban el poder militar de la Unión Soviética como una grave amenaza para los Estados Unidos, mientras que el 60 por cien de la gente y el 63 por cien de los dirigentes creian que el poder económico del Japón sí constituía tal amenaza. Suzanne Berger y Kenneth A. Oye, "America's Enemy is not Japan but America's own Shortcomings", Internacional Herald Tribune, 9-12-1991, pág, 8.

40. Una opinión contraria, que llega a decir que "el Acta Final no consiguió gran cosa" en Ralf Dahrendorf. Reflexiones sobre la revolución en Europa, Emecé editores, Barcelona, 1991, pág. 144.

41. Esta idea gorbachoviana (v. Mijail Gorbachov, Perestroika, cit., págs. $180 \mathrm{y}$ sigs.) resultó inviable precisamente en el momento de su formulución pues en seguida fue claro que si la URSS buscaba la casa común en Europa, Europa por ello mismo entraría en proceso de turbulencia y trastorno de fronteras, como así ha sido y cuyo resultado sólo podrá verse al final de este agitado 'período.

42. De hecho, la Comisión de la UE coordina actualmente un programa de ayuda de los países industriales a los ex-socialistas de 40.000 millones de dólares (aproximadamente cuatro billones de pesetas); si ello parece ya mucho, jiénsese que sólo la República Federal de Alemania lleva desembolsados a favor de la ex-Unión Soviética $\mathbf{6 0 . 0 0 0}$ millones de dólares o seis billones de pesetas. Der Spiegel, año $45, n^{43} 37,9$ de septiemlore de 1991. 